\title{
AVALIAÇÃO DO COMPORTAMENTO FÍSICO E MECÂNICO DE BLOCOS DE CONCRETO ECOLÓGICOS FABRICADOS COM INCORPORAÇÃO PARCIAL DE UM RESÍDUO SÓLIDO INDUSTRIAL
}

\author{
R. F. BERTOLI ${ }^{1}$, G. L. KRAMEL ${ }^{2}$, J. G. SGORLON ${ }^{2}$, M. C. S. GOMES ${ }^{1}$, M. L. MENEZES ${ }^{2}$ \\ ${ }^{1}$ Universidade Tecnológica Federal do Paraná, Processos Químicos \\ ${ }^{2}$ Universidade Tecnológica Federal do Paraná, Engenharia Química \\ E-mail para contato: renan_bertoli@hotmail.com
}

\begin{abstract}
RESUMO - O presente trabalho tem como objetivo o reaproveitamento de um resíduo sólido industrial na fabricação de blocos de concretos para pavimentação. O resíduo depois de coletado foi caracterizado química e fisicamente. Posteriormente, foram confeccionados blocos de concreto utilizando formulações com $2 \%, 3 \%, 4 \%, 5 \%$ e $10 \%$, de resíduo. Os resultados de resistência à compressão e absorção de água dos blocos mostraram a viabilidade de utilização de até $10 \%$ de resíduo na formulação do concreto sem perda de qualidade das peças, bem como a possibilidade de reutilização/tratamento desse tipo de rejeito.
\end{abstract}

\section{INTRODUÇÃO}

As indústrias são consideradas grandes geradoras de resíduos poluentes ao ambiente, pela própria transformação dos recursos naturais em bens de consumo. Com isso, o processamento de materiais resulta na produção de grandes quantidades de substâncias, algumas agressivas ao homem e ao meio, as quais, muitas vezes não possuem aplicabilidade imediata, resultando em interferências em todo o processo de equilíbrio dos ecossistemas devido ao seu tratamento e disposição inadequados.

Muitos dos resíduos industriais podem apresentar-se na forma sólida, líquida ou gasosa, afetando locais muitas vezes distantes do local de sua geração (PABLOS, 2008). No Brasil, apesar do gerenciamento dos resíduos gerados pelas indústrias ser composto de grandes desafios, a reutilização pode ser considerada como alternativa em muitos casos, para fins tais como, pavimentação de estradas, incorporação na construção civil, incorporação ao solo, entre outros.

Com isso, o objetivo do presente trabalho é avaliar o comportamento físico e mecânico de blocos de concretos fabricados de forma ecológica com incorporação parcial de um resíduo sólido industrial. 


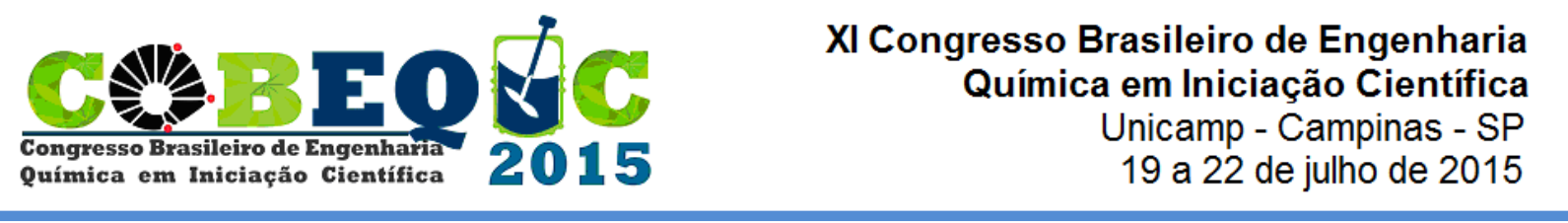

\section{MATERIAIS E MÉTODOS}

\subsection{Caracterização do Resíduo}

O resíduo utilizado na fabricação dos blocos de concreto foi coletado diretamente de uma indústria de galvanoplastia localizada na região de Piabiru - PR. O resíduo após coletado foi acondicionado em bombas plásticas devidamente lacradas e guardadas em local protegido.

A caracterização física: Foi realizada por meio do ensaio de granulometria segundo a norma ABNT NBR 7181 (1984).

A caracterização química: Foi realizada por meio das análises de fluorescência de raios$\mathrm{x}$ (FRX) em espectrômetro de raios-x Rigaku, modelo ZSX Mini II, e lixiviação/solubilização, com limites de concentração de contaminantes estabelecidos pelas normas ABNT NBR 10005 (2004) e ABNT NBR 10006 (2004), respectivamente. As amostras para as análises químicas foram coletadas da superfície de fratura dos corpos-deprova rompidos nos ensaios de resistência a compressão na idade de cura de 28 dias.

\subsection{Caracterizações dos Blocos de Concreto para Pavimentação}

A fabricação dos blocos de concreto foi realizada na Fábrica de Artefatos da Universidade Estadual de Maringá e os pavimentos produzidos tiveram dimensões de $100 \mathrm{~mm}$ (largura) x $200 \mathrm{~mm}$ (comprimento) x $80 \mathrm{~mm}$ (altura). Os equipamentos necessários para a fabricação foram: equipamentos manuais (carriola e pás) para homogeneização e confecção da pasta de concreto e vibro-prensa semi-automática pneumática, para a moldagem dos blocos de concreto.

Para a fabricação dos blocos de concreto é necessário o estabelecimento das quantidades de cada matéria-prima para a fabricação do concreto, essas quantidades são denominadas "traço" do concreto. No presente trabalho foi utilizado o traço referência estabelecido por Franco (2011), que estudou a incorporação de resíduos de galvanoplastia na fabricação de blocos de concreto para pavimentação e obteve ótimos resultados em seus estudos.

Caracterização mecânica: Foi realizada por meio dos ensaios de resistência a compressão, segundo as recomendações da nova norma ABNT NBR 9781 (2013): Peças de concreto para pavimentação, na idade de cura de 28 dias.

Caracterização física: Foi realizada por meio dos ensaios de determinação da absorção de água que foram baseados na metodologia proposta pela ABNT NBR 9781 (2013), também na idade de 28 dias de cura.

Para maior confiabilidade, os resultados de resistência à compressão e absorção de água foram submetidos aos testes estatísticos de Análise de variância (ANOVA) e teste de Tukey. Foi utilizado o software STATISTICA 8.0 para a realização do estudo. 


\section{RESULTADOS E DISCUSSÕES}

\subsection{Caracterização do Resíduo}

A Tabela 1 e a Figura 1 apresentam à análise granulométrica do resíduo utilizado na incorporação dos blocos de concreto.

Tabela 1 - Análise granulométrica do resíduo industrial.

\begin{tabular}{ccccccc}
\hline Mesh & $\begin{array}{c}\text { Abertura } \\
(\mathrm{mm})\end{array}$ & $\begin{array}{c}\text { Massa da } \\
\text { peneira (g) }\end{array}$ & $\begin{array}{c}\text { Massa } \\
\text { retida (g) }\end{array}$ & Retido (\%) & $\begin{array}{c}\text { Retido acumulado } \\
\text { acima (\%) }\end{array}$ & $\begin{array}{c}\text { Retido } \\
\text { acumulado } \\
\text { abaixo (\%) }\end{array}$ \\
\hline 80 & 0,180 & 392,37 & 205,98 & 41,31 & 41,31 & 58,69 \\
100 & 0,150 & 319,07 & 59,31 & 11,89 & 53,20 & 46,80 \\
170 & 0,090 & 299,96 & 140,69 & 28,21 & 81,41 & 18,59 \\
270 & 0,053 & 306,19 & 66,74 & 13,38 & 94,79 & 5,21 \\
400 & 0,036 & 300,13 & 21,90 & 4,39 & 99,18 & 0,82 \\
Fundo & & 298,86 & 4,06 & 0,82 & 100 & 0 \\
Soma & & & 498,68 & 100 & & \\
\hline
\end{tabular}

Figura 1 - Distribuição granulométrica do resíduo.

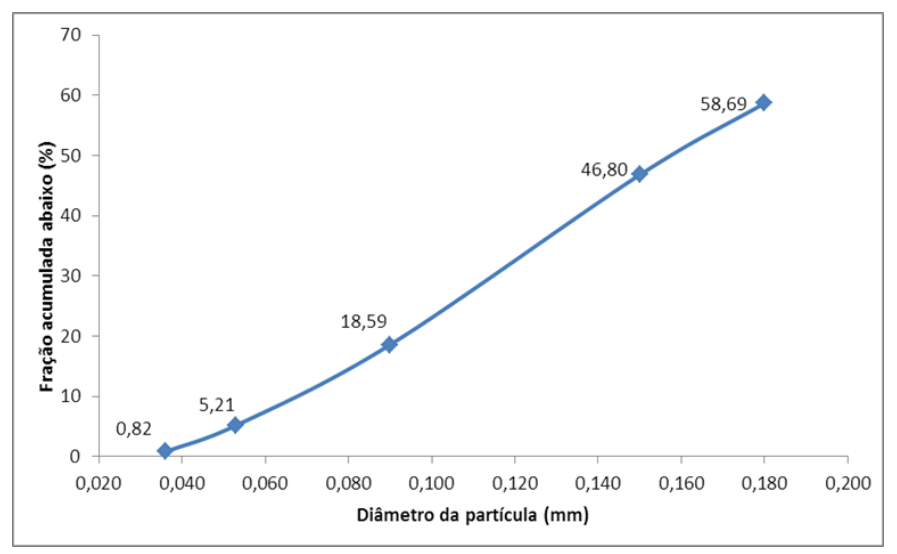

Por meio dos resultados foi possível verificar que a distribuição granulométrica do resíduo industrial utilizado na fabricação dos blocos encontrou-se entre as faixas granulométricas de $0,018 \mathrm{~mm}$ e $0,036 \mathrm{~mm}$

Na Tabela 1 observou-se a retenção de resíduo em todas peneiras, até mesmo no fundo, ou seja, há algumas partículas $(0,82 \%)$ com diâmetros menores que $0,036 \mathrm{~mm}$. A abertura que obteve maior retenção de partículas do resíduo foi a de $0,180 \mathrm{~mm}$, retendo cerca de $41,31 \%$ da massa de resíduo industrial analisado. Segundo Ortigão (2007), pode-se classificar o resíduo na faixa granulométrica de finos, quando comparado com a curva granulométrica da areia. 
Na Tabela 2 encontram-se os resultados da análise de fluorescência de raios-x do resíduo utilizado. Essa análise é fundamental, pois permite avaliar qualitativamente os minerais presentes no resíduo.

Tabela 2 - Fluorescência de raios-x: porcentagem em massa dos compostos presentes na composição do resíduo.

\begin{tabular}{c|c|c|c}
\hline Óxidos & (\% massa) & Óxidos & (\% massa) \\
\hline $\mathbf{M g O}$ & 71,77 & $\mathbf{Z n O}$ & 0,02 \\
$\mathbf{A l}_{2} \mathbf{O}_{3}$ & 10,95 & $\mathbf{S O}_{3}$ & 0,09 \\
$\mathrm{SiO}_{2}$ & 12,48 & $\mathbf{C u O}$ & 0,02 \\
$\mathbf{P}_{2} \mathbf{O}_{\mathbf{5}}$ & 0,44 & $\mathbf{M n O}$ & 0,13 \\
$\mathrm{CaO}$ & 3,04 & $\mathrm{Cr}_{2} \mathbf{O}_{3}$ & 0,07 \\
$\mathrm{Fe}_{2} \mathbf{O}_{3}$ & 0,99 & & \\
\hline
\end{tabular}

O composto presente em maior quantidade no resíduo, com $71,77 \%$, é o óxido de magnésio $(\mathrm{MgO})$. Esse valor elevado está relacionado a origem do resíduo utilizado (indústria de resistências elétricas e de galvanoplastia). A sílica $\left(\mathrm{SiO}_{2}\right)$, também apresentou porcentagem mássica considerável na matriz do resíduo $(12,48 \%)$ pois, na indústria onde o rejeito foi coletado, utilizam no jateamento das peças a serem galvanizadas microesferas de vidro, o que pode ter causado algum tipo de contaminação. $\mathrm{O}$ óxido de alumínio $\left(\mathrm{Al}_{2} \mathrm{O}_{3}\right)$ também apresentou 10,95\% em massa no resíduo, a presença desse óxido pode estar vinculada ao desgaste de equipamentos, composição das peças galvanizadas ou até mesmo contaminação de agentes externos, algo muito comum nas indústrias de galvanoplastia.

\subsection{Caracterização dos Blocos de Concreto Fabricados}

Na Figura 2 encontram-se a média dos resultados de absorção de água dos blocos de concreto com incorporação do resíduo industrial na idade de cura de 28 dias.

Figura 2 - Absorção de água dos blocos de concreto fabricados com o resíduo.

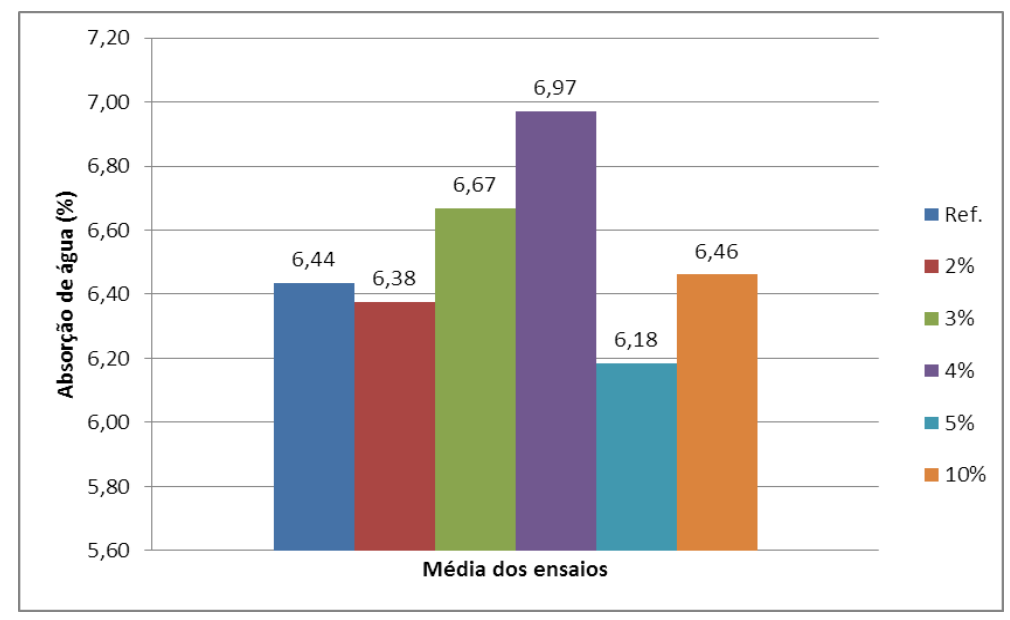


Por meio da Figura 2 é possível observar que os valores médios de absorção de água dos blocos foram levemente superiores a $6 \%$ (valor máximo permitido pela norma $\mathrm{ABNT}$ NBR 9781 (2013), sendo na incorporação de 4\% o pico de maior absorção de água.

Por meio da realização da análise de variância (ANOVA) referente aos resultados de absorção de água com $99 \%$ de confiança, foi possível verificar que o Pvalor para a absorção de água dos blocos foi de 0,2065 (Pvalor > 0,01), ou seja, não houve diferença significativa entre as médias dos ensaios. Com isso, é possível afirmar que a incorporação de até $10 \%$ de resíduo na fabricação dos blocos de concreto não altera a propriedade física de absorção de água das peças.

A Figura 3 apresenta as médias de resistência à compressão dos blocos de concreto fabricados com o resíduo, bem como do bloco referência.

Figura 3 - Resistência a compressão dos blocos de concreto fabricados com o resíduo.

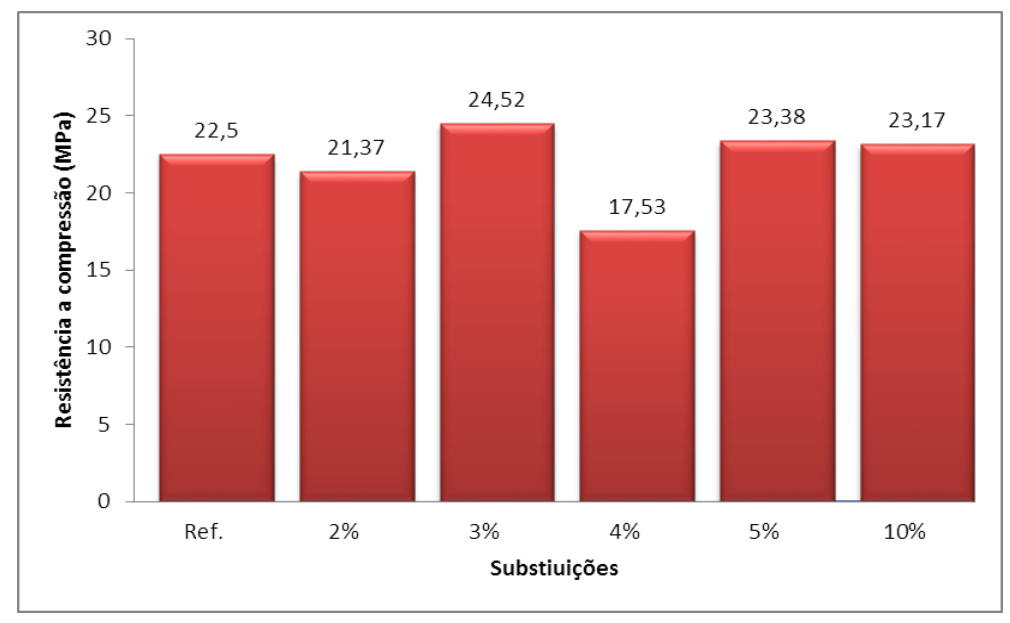

Por meio dos resultados da análise de variância (ANOVA) realizada nas médias de resistência à compressão dos blocos, pode-se verificar com $99 \%$ de confiança que, estatisticamente, existe diferenças significativas entre as médias dos ensaios, pois o Pvalor do tratamento foi de 0,0091 (Pvalor $<0,01$ ) ao nível de $1 \%$ de probabilidade.

Para determinar quais os tratamentos tiveram suas médias estatisticamente diferentes entre si, foi necessário aplicar outro tratamento. Nesse caso utilizou-se o Teste de Tukey para encontrar quais foram as médias que diferiram.

As médias dos tratamentos que apresentaram diferenças significativas em seus valores foram as médias de resistência à compressão dos blocos fabricados com $3 \%$ e $4 \%$ de resíduo. No entanto, a resistência à compressão dos blocos referência e fabricados com $10 \%$ de resíduo, quando comparados pelo teste de Tukey, não apresentaram diferenças significativas. Assim, pode-se dizer que a incorporação de $10 \%$ de resíduo industrial em substituição ao agregado miúdo do concreto não afetou os valores de resistência à compressão dos blocos. 


\section{CONCLUSÃO}

O reaproveitamento/tratamento de resíduos sólidos industrias para fabricação de blocos de concreto ecológicos está se tornando cada vez mais uma alternativa para a destinação adequada e com ganhos ambientais. Para isso foi necessário analisar o comportamento do resíduo quando incorporado em matriz cimentícia, para a definição da proporção ideal de resíduo para fabricação dos mesmos, sem afetar sua qualidade.

Os resultados do ensaio de absorção de água dos blocos com incorporação de $2 \%, 3 \%$, $4 \%, 5 \%$ e $10 \%$ de resíduo apresentaram-se dentro dos limites estabelecidos pela norma NBR 9781 (2013), quando comparados individualmente, não interferindo na qualidade dos blocos. Os resultados de resistência à compressão dos blocos de referência e fabricados com incorporação de $10 \%$ de resíduos, também não diferenças significativas estatisticamente.

Portanto, conclui-se que a utilização de $10 \%$ de resíduo sólido industrial galvânico em substituição ao agregado miúdo do concreto utilizado na fabricação dos blocos, não comprometeu as características físicas e mecânicas das peças, proporcionando uma ótima qualidade aos blocos fabricados, bem como uma possibilidade de reutilização/tratamento desse tipo de rejeito.

\section{REFERÊNCIAS}

ABNT. ASSOCIAÇÃO BRASILEIRA DE NORMAS TÉCNICAS. NBR 7181: SoloAnálise Granulométrica. Rio de janeiro, ABNT, 1984.

NRB 9781. Peças de concreto para pavimentação - especificação e métodos de ensaio. Rio de Janeiro, 2013.

. NBR 10004. Resíduos Sólidos - Classificação. Rio de Janeiro, 2004.

NBR 10005. Procedimento para Obtenção de Extrato Lixiviado de Resíduos Sólidos. Rio de Janeiro, 2004.

NBR 10006. Procedimento para Obtenção de Extrato Solubilizado de Resíduos Sólidos. Rio de Janeiro, 2004.

FRANCO, J. M. Produção de blocos de concreto para pavimentação (BCP) utilizando resíduos de galvanoplastia. 2011. Dissertação - Departamento de Engenharia Civil, Pós-Graduação em Engenharia Urbana, Universidade Estadual de Maringá, Maringá, 2011.

ORTIGÃO, J. A . R. Introdução à mecânica dos solos dos estados críticos. $3^{\mathrm{a}}$ ed. Terratek, 2007.

PABLOS, J. M. Estudo para a reutilização do resíduo sólido constituído pelas areias de fundição aglomeradas com argila, através da técnica de solidificação/estabilização em matrizes de cimento Portland, para aplicação no setor da construção civil. Tese Doutorado em Arquitetura e Urbanismo, Universidade de São Paulo, São Carlos, 2008. 